\title{
A educação ambiental nas universidades públicas estaduais do Paraná: uma análise a partir dos documentos institucionais
}

Environmental education in public universities state of Paraná: an analysis from the corporate documents

\author{
Vania Silva de Souza Bilert ', Rodrigo Lingnau ${ }^{2}$, Marlize Rubin Oliveira ${ }^{3}$ \\ I Mestre em Desenvolvimento Regional, Universidade Estadual do Centro-Oeste- UNICENTRO, PR, Brasil \\ ${ }^{2}$ Doutor em Biociências (Zoologia), Universidade Tecnológica Federal do Paraná, UTFPR, PR, Brasil \\ ${ }^{3}$ Doutora em Educação, Universidade Tecnológica Federal do Paraná, UTFPR, PR, Brasil
}

\begin{abstract}
Resumo
A produção do conhecimento é o principal fator que culmina na transformação da sociedade. Por meio do conhecimento, é possível antecipar problemas e soluções que possam emergir na sociedade, e a universidade como instituição educativa tem o papel central nas discussões sobre os diversos problemas presentes na sociedade, entre eles os problemas ambientais. Neste sentido, objetiva-se com este artigo apresentar como a educação ambiental está inserida nos documentos institucionais de seis universidades públicas estaduais no Paraná. Os dados da pesquisa foram coletados a partir da análise do Plano de Desenvolvimento Institucional (PDI) e Projeto Político-Pedagógico Institucional (PPI), das universidades selecionadas para o estudo. De maneira geral, a pesquisa demonstra, com base na análise documental, que apesar da Educação Ambiental ser um processo ainda novo, a discussão ambiental já está sendo mais amadurecida nas universidades.
\end{abstract}

Palavras-chaves: Educação Ambiental, Universidade, Documentos institucionais.

\begin{abstract}
The production of knowledge is the main factor that culminates in the transformation of society. Through the knowledge you can anticipate problems and solutions that may emerge in society, and the university as an educational institution has the central role in the discussions on the various problems in society, including environmental problems. In this sense, the objective is to present this article as environmental education is embedded in institutional documents six state universities in Paraná. The survey data were collected from the analysis of the Institutional Development Plan (IDP) and Institutional Political-Pedagogical Project (IPP), the universities selected for the study. Overall, the research demonstrates, based on documentary analysis, in spite of Environmental Education still be a new process, now being more mature universities in environmental discussion.
\end{abstract}

Keywords: Environmental Education, University , Institutional documents . 


\section{INTRODUÇÃO}

Nos últimos anos, a exploração da natureza tem se intensificado cada vez mais. Admite-se, assim, que a necessidade iminente de repensar as relações entre homem e natureza fez com que o termo "Educação Ambiental" passasse a figurar no campo educacional, considerando a Educação Ambiental, como um processo educativo que preocupa-se com as novas configurações do relacionamento homem-natureza, com os problemas decorrentes da ação antrópica do homem na natureza e com desenvolvimento sustentável.

Logo, o campo educacional, neste caso especificamente a universidade, possui o desafio constante de propiciar conhecimentos, saberes, que contemplem uma formação atualizada com o contexto dos problemas emergentes da sociedade, e isso também requer profissionais preparados para lidar com tais problemas, com conhecimentos amplos sobre a sua área de atuação, legislações e regulamentações que subsidiarão os diversos processos educativos.

Nesta perspectiva, é necessário destacar que a universidade detém a atribuição de produzir conhecimentos em consonância com as demandas do mercado e as necessidades da sociedade em determinado espaço temporal, através da articulação entre ensino, pesquisa e extensão.

Cabe evidenciar que, embora a educação ambiental seja regulamentada pela Política Nacional de Educação Ambiental através da Lei no 9.795, de 1999, que prevê a inserção da Educação Ambiental em todos os níveis e modalidades de ensino, o que se verifica, conforme o relatório da Rede Universitária de Programas de Educação Ambiental para Sociedades Sustentáveis - RUPEA, é que a institucionalização da Educação Ambiental ainda não faz parte da formação dos profissionais de nível superior (RUPEA, 2005).

Desta forma, cientes de que a discussão ambiental é cada vez mais necessária na sociedade, e principalmente dos temas que a universidade deve contemplar no processo de ensino, pesquisa e extensão, a questão a ser respondida neste estudo é: A educação ambiental está presente nas discussões das universidades públicas estaduais no estado do Paraná?

Para responder a este questionamento, o objetivo geral deste estudo é verificar como a educação ambiental está inserida nos documentos institucionais - Plano de Desenvolvimento Institucional (PDI) e Projeto Político-Pedagógico Institucional (PPI) - das universidades.

Este estudo, por seu turno, fundamenta-se na perspectiva da educação ambiental crítica, pois compreende que a educação ambiental deve ir além de uma proposta pedagógica que visa à transmissão de conhecimentos para a utilização racional dos recursos naturais, mas que se consolide através de um processo de reflexão, conscientização e sensibilização, que leve em consideração as relações e inter-relações entre homem e natureza.

Nesta perspectiva, o estudo baseia-se no pressuposto de que a universidade é o espaço de capacitação de profissionais que vai atuar em diferentes setores da sociedade, muitos dos quais desempenhando papel de líderes e formadores de opinião. Neste sentido, o aprofundamento das discussões surge no contexto da importância de agregar aos acadêmicos uma formação socioambiental, de modo que estes possam contribuir com o desenvolvimento sustentável local, regional e global, direcionando um novo relacionamento entre homem e natureza. Por conseguinte, a partir da integração do conhecimento ambiental, tanto a formação humana como a formação profissional destes sujeitos serão beneficiadas.

\section{PROCEDIMENTOS METODOLÓGICOS}

Para a realização desta pesquisa foram selecionados os critérios de escolha das universidades, sendo especificado como as universidades públicas estaduais do estado do Paraná. Desta forma, a pesquisa foi realizada em seis instituições de ensino superior pública no estado do Paraná, assim identificadas: Universidade Estadual de Londrina - UEL, Universidade Estadual de Maringá - UEM; Universidade Estadual do Norte do Paraná - UENP; Universidade Estadual de Ponta Grossa - UEPG; Universidade Estadual do Centro-Oeste - UNICENTRO; e Universidade Estadual do Oeste do Paraná - UNIOESTE.

Desta forma, após a definição das universidades, a próxima etapa metodológica refere-se a análise documental, Lüdke e André (1986), observam que "os documentos surgem a partir de um determinado contexto e fornecem informações sobre esse mesmo contexto". De acordo com Martins 
(2008), a pesquisa documental é necessária tanto para facilitar o entendimento do caso, e também para corroborar evidências, triangulação de dados e resultados.

É salutar destacar que os documentos selecionados para a análise documental foram o Plano de Desenvolvimento Institucional (PDI) e o Projeto Pedagógico Institucional (PPI). De acordo com Franco (2008), a análise documental propicia identificar informações nos documentos a partir de questões ou hipóteses de interesse, que neste caso, concentrou-se em verificar como a educação ambiental está inserida nos documentos institucionais - PDI e PPI - nas universidades.

A análise dos documentos institucionais, foi realizada nos meses de janeiro e fevereiro de 2013, e os documentos analisados foram os que estavam disponíveis nos sites das universidades, nesta época. Vale destacar, que a pesquisadora preocupou-se em analisar os documentos em vigência.

É importante evidenciar que a análise dos documentos teve como ênfase os aspectos que fizessem menções a temática ambiental, integrando a problemática socioambiental às relações sociais, econômicas, políticas e culturais. Embora alguns excertos selecionados não apresentaram menção direta ao adjetivo ambiental, muitos foram analisados a partir da vinculação com a problemática ambiental.

\section{RESULTADOS E DISCUSSÃO}

\subsection{Compreendendo a legislação estadual}

Seguindo as diretrizes da Agenda 21 Brasileira - documento formalizado a partir da Conferência das Nações Unidas sobre Meio Ambiente e Desenvolvimento Rio-92, realizada no Rio de Janeiro em 1992 - da Conferência de Joannesburg de 2002, firmou-se o compromisso com a implementação de ações, estratégias e planos que foram se configurando em âmbito nacional, com participação do setor público, privado, entidades não governamentais e diversos segmentos da sociedade (SEMA, 2009).

Nesta perspectiva, a Agenda 21 foi um documento assinado por 179 países, dentre eles o Brasil, e todos estes países assumiram o compromisso na construção de um desenvolvimento sustentável. Especificamente com relação ao estado do Paraná, é importante destacar, que realizou-se em 2001, um amplo debate com a participação de representantes do governo e sociedade civil; e nesta ocasião foi firmado o compromisso do Governo do Estado em implementar a Agenda 21 Paraná. O objetivo da Agenda 21 Paraná, alicerçado na Agenda 21 Global, possui como princípios a construção da sustentabilidade ambiental, social e econômica, na perspectiva de um novo padrão de desenvolvimento (SEMA, 2009).

O governo do estado do Paraná, estabeleceu em 2004 o Decreto Governamental n ${ }^{\circ} 2547$, de 04 de fevereiro de 2004. Desta forma, o decreto criou o Fórum Permanente da Agenda 21 Paraná, formado por diversas instituições governamentais e não governamentais, com destaque as Instituições de Ensino Superior (AGENDA 21 PARANÁ, 2004)

Especificamente sobre o compromisso das Instituições de Ensino Superior (IES), foi firmado em 2007 o Pacto 21 Universitário, baseado em três pilares: institucionalização, divulgação e promoção de alternativas sustentáveis. O Pacto 21 Universitário for firmado pela Ministra do Meio Ambiente Marina Silva e o Governador do Estado na época Roberto Requião, além de treze representantes de instituições públicas e privadas de Ensino Superior do Estado (SEMA, 2009).

O Pacto Universitário foi assinado por 13 instituições de ensino superior, pública e privada, do estado do Paraná, que se comprometeram a inserir uma nova perspectiva para o desenvolvimento sustentável. Dentre as 13 instituições de ensino superior, destaca-se a Universidade Estadual de Londrina - UEL, Universidade Estadual do Centro-Oeste - UNICENTRO e a Universidade Estadual do Oeste do Paraná - UNIOESTE, ou seja, das 6 universidades selecionadas para este estudo, apenas 3 integram o Pacto 21 Universitário (SEMA, 2009).

O Pacto 21 Universitário evidencia os seguintes princípios destacados pela SEMA (2009):

a) institucionalizar, através de práticas de ensino, pesquisa, extensão, programas e ações os princípios da Agenda 21 do Paraná;

b) divulgar o contexto da Agenda 21 Paraná, através da formação de multiplicadores e disseminação de conteúdos;

c) promover o pensamento reflexivo, para tomada de atitudes transformadoras, com vistas a sustentabilidade. 
Neste sentido, um dos papéis das IES é de integrar aos currículos de ensino e as atividades de pesquisa, o principio preconizado no cap. 36 da Agenda 21 Global, conferindo ao ensino "consciência ambiental, ética, valores e atitudes técnicas e comportamentos em consonância com o desenvolvimento sustentável que favoreçam a participação pública e efetiva nas tomadas de decisões" (SEMA, 2009).

Todavia, o entendimento dos objetivos do Pacto 21 Universitário, evidencia um questionamento, será que as universidades que firmaram o acordo estão conduzindo suas ações, estratégias e planos, além de conduzir através do ensino e pesquisa a consciência ambiental? A resposta para este questionamento, será contextualizada a partir na análise dos documentos institucionais apresentados a seguir.

\subsection{O que apresentam os documentos institucionais}

A análise dos documentos institucionais: Plano de Desenvolvimento Institucional (PDI) e o Projeto Pedagógico Institucional (PPI), tem o objetivo de apresentar a presença da educação ambiental nos documentos, destacando que os documentos selecionados orientam as universidades em seus planejamentos e ações nos pilares do ensino, pesquisa e extensão.

O Plano de Desenvolvimento Institucional (PDI) é um documento que visa determinar a missão, metas, objetivos, estratégias, diretrizes pedagógicas que orientará as ações, estrutura organizacional e atividades que subsidiarão o desenvolvimento das instituições de ensino. É um documento que cumpre exigências da LDB (Lei de Diretrizes e Bases da Educação), sendo elaborado para um período de cinco anos (MEC, 2006). Cabe ressaltar também, que o Plano de Desenvolvimento Institucional (PDI), é um documento regulado pela Lei $n^{\circ} 10.861 / 2004$, Decreto $n^{\circ} 5773 / 2006$ e pela Portaria do MEC $n^{\circ}$ 40/2007.

Assim, o PDI deve ser reconhecido como um documento fundamental com relação à filosofia de trabalho da Instituição da Ensino Superior (IES), na determinação de princípios e valores das instituições.

Outro documento que orienta a política pedagógica da Instituição, é o Projeto Pedagógico Institucional (PPI), sendo considerado um instrumento teórico-metodológico que norteará as práticas acadêmicas para o exercício do ensino, pesquisa e extensão. Ressalta-se que o PDI sustenta o PPI, e em alguns casos, o PPI também pode ser um elemento contextualizado no próprio PDI.

Por sua vez, tais documentos orientam os Projetos Políticos Pedagógicos dos Cursos (PPC's), que deve manter uma relação com o Plano de Desenvolvimento Institucional (PDI). No entanto, os documentos visam articular e assegurar o desenvolvimento no contexto universitário, abrangendo uma formação profissional e cidadã.

Neste panorama de análise, pode-se destacar que a análise dos documentos da UEL preconiza nas políticas de ensino de graduação, as diretrizes pedagógicas para os Projetos Pedagógicos dos Cursos - PPC's, e evidencia a necessidade de que os conteúdos visem "estimular o conhecimento dos problemas do mundo presente, em particular os nacionais e regionais [...]" (UEL, 2010, p. 21). Observa-se que não está presente no excerto o adjetivo ambiental, todavia, pode-se inferir que se a problemática ambiental for compreendida na perspectiva de problemas do mundo presente, tal discussão pode estar inserida nos Projetos Pedagógicos dos Cursos, o que culmina para a inserção da dimensão ambiental no ensino.

$\mathrm{Na}$ análise dos documentos da UENP identificou-se que a universidade objetiva um ensino que vise a formação reflexiva e crítica, que proporcione uma articulação dos conhecimentos contemplados na universidade face aos desafios mundiais contemporâneos, além de "incentivar atividades que visem a preservação ambiental e a qualidade de vida" (UENP, 2012, p. 46).

A partir da análise dos documentos da UENP, observou-se que coincide com a UEL, a necessidade de que em suas matrizes curriculares sejam contemplados temas contemporâneos, relevantes para a formação do egresso, primando pela interdisciplinaridade no processo de ensino (UENP, 2012).

Esta concepção de discussões da problemática atual, corrobora o argumento da Fávero (2006) ao destacar que a universidade deve ser um espaço de discussões sobre a sociedade "em que se desenvolve um pensamento teórico-crítico de ideias, opiniões, posicionamentos, como também o encaminhamento de propostas e alternativas para solução dos problemas" (FÁVERO, 2006, p. 19).

Com relação a análise dos documentos da UEPG, observou que o compromisso com o ensino e a extensão devem ter como "relevância acadêmica, uma relevância social, privilegiando problemáticas de pesquisa que estejam relacionadas ao desenvolvimento humano e ao desenvolvimento ambiental sustentável" (UEPG, 2008, p. 59). 
Com relação a UNICENTRO observou na análise, que a grande preocupação da universidade no que tange a Políticas de Ensino, é "superar a dicotomia entre formação humanística e racionalidade técnica, oxigenando os currículos de forma a possibilitar que os discentes transitem pelas várias áreas de conhecimento sem perder o foco de formação [...]" (COU/UNICENTRO, 2009, p. 02).

Pode-se inferir, a partir da análise do excerto, a necessidade da transversalidade e interdisciplinaridade, nas diversas áreas; que além de propiciar uma formação profissional sólida também cumpre seu papel de formação cidadã. Desta forma, a partir da compreensão de que os problemas atuais estão cada vez mais multidisciplinares e transversais, a educação ambiental é enfatizada como um tema transversal, que apresenta relações com várias áreas do conhecimento (CARPOLINGUA, 2012; MORIN, 2003).

Constatou-se também, na análise do PDI da UNICENTRO, que a universidade possui como base de suas políticas de ensino o objetivo de uma "formação integral de sujeitos de tal modo que sejam a um só tempo profissionais mas também cidadãos, eficientes mas também críticos [...]" (COU/ UNICENTRO, 2009, p. 18).

É dever da universidade colaborar para o desenvolvimento do pensamento crítico, na busca de soluções que possam auxiliar no enfrentamento das causas de degradação ambiental; "caso contrário, será apenas, quando muito, uma universidade que atribui títulos e possibilita empregos melhores ou ainda realiza pesquisas financiadas pelos interesses das grandes corporações empresariais" (SORRENTINO et al. 2012, p. 25).

A UNICENTRO evidencia nos documentos com relação as Políticas nas áreas de Pesquisa e Pós-Graduação a ênfase as "respostas aos problemas e questionamentos da região onde se insere, sejam econômicos, sociais, científicos e culturais, em âmbito nacional e internacional (COU/UNICENTRO, 2009, p. 19).

Trata-se, assim, de uma discussão que deve ser contextualizada para além dos discursos, em um processo de repensar os efeitos das práticas educativas de educação ambiental, e de como integrar a problemática ambiental as relações sociais, econômicas, políticas e culturais (FARIAS, 2008). O fato é que "a universidade, como instituição privilegiada para a formação de intelectuais, precisa aprender a trabalhar com recursos sociais, possibilitar a atuação e o relacionamento com saberes e competências" (SORRENTINO et al., 2012, P. 22).

A partir da análise dos documentos da UNIOESTE, pode-se evidenciar que a universidade tem como princípio a responsabilidade social, ambiental e cultural, o que indica a necessidade da incorporação de tais dimensões no ensino.

As Diretrizes Curriculares Nacionais (2012) ressaltam que a Educação Ambiental deve estar embasada em um processo para a formação de uma nova cidadania, é para isso é necessário que as instituições de ensino sejam incubadoras de mudanças concretas na realidade social.

É contundente evidenciar, que mesmo sem os documentos mencionarem qualquer relação com o Pacto 21 Universitário, observa-se que intrinsecamente as ações do Pacto 21 estão presentes nas diretrizes dos documentos institucionais.

Com relação a educação ambiental na pesquisa, ressalta-se que das seis universidades pesquisadas, apenas três evidenciaram em seus documentos menções a educação ambiental relacionadas as atividades de pesquisa, sendo a UENP,UEPG e UNICENTRO.

Observa-se que é recorrente nos documentos a preocupação com as inter-relações das dimensões sociais, políticas, culturais, econômicas, ambientais; o que corrobora o ponto de vista de Jacobi (2003), ao citar que a produção do conhecimento deve ser centrada na perspectiva do novo perfil de desenvolvimento, que enfatize a sustentabilidade ambiental, e que consequentemente resultará em ações alternativas em prol de um novo desenvolvimento.

Observa-se que existe uma carência nos documentos de menções a necessidade de pesquisas em educação ambiental, no entanto, os resultados da pesquisa realizada pela RUPEA (2005) mostrou que a pesquisa é a mais evidenciada quando se trata de projetos de educação ambiental, apresentando um percentual de $86 \%$ das 22 instituições de ensino superior pesquisadas.

É prudente a necessidade de realização de mais pesquisas com ênfase as questões ambientais, pois como afirma Sorrentino (2012), o papel central na produção do conhecimento, diagnóstico e soluções para os diversos problemas vivenciados pela sociedade, está em grande parte centrado nas pesquisas universitárias. O mesmo raciocínio é defendido por Torales (2012) ao argumentar que é necessário o desenvolvimento de pesquisas sobre a temática ambiental. 
Outro ponto de destaque da análise é com relação as práticas extensionistas. Neste sentido, é preciso considerar que as práticas extensionistas propiciam a efetivação de um processo educativo atrelado com a indissociabilidade e viabilização da relação entre universidade e sociedade, pois somente a partir de um processo educativo com vistas a interação, é que possibilitará a troca de valores, cultura e transformação do meio. É uma troca de saberes, no qual a universidade leva conhecimentos a sociedade/comunidade e também aprende, é a interação entre o saber acadêmico e popular.

De acordo com a análise dos documentos da UEL, pode-se verificar a presença da educação ambiental na extensão no excerto que apresenta a necessidade de "priorizar práticas voltadas ao atendimento a necessidades sociais emergentes [...] e pensar a educação ambiental e o desenvolvimento sustentado como componentes da atividade extensionista" (UEL, 2010, p. 68). Ressalta-se baseado no relatório RUPEA (2005) que a educação ambiental para a universidade é uma demanda social emergente; neste mesmo raciocínio Fávero (2006) cita que é dever da universidade ainda assumir o papel de equacionar respostas às necessidades emergentes.

O PDI da UEM, destaca que é "por meio da extensão, estabelece-se o compromisso social das universidades de tornar o desenvolvimento sustentável do entorno local e regional uma meta a ser alcançada pelas universidades e, sobretudo pela Extensão" (UEM, 2009, p. 37). Na análise, identificou-se que existe na universidade vários grupos e núcleos em várias áreas do conhecimento, e que tem procurado desenvolver atividades e ações extensionistas voltadas para a questão ambiental. Um aspecto importante evidenciado nas análises, é que os documentos da UEM destacam a ênfase da educação ambiental somente nos projetos extensionistas.

Verificou-se na análise dos documentos da UENP, especificamente no capítulo 4, do PDI, que é ressaltado as ações para a extensão universitária, e destaca a necessidade de desenvolver ações que "contemplem as grandes questões político-sociais, tais como: educação, saúde, meio ambiente [...] e, articulação do "projetos de preservação do meio ambiente" (UENP, 2012, 48-49).

Os resultados referentes aos documentos da UEPG evidenciam que um dos objetivos da política de extensão é "oportunizar ações extensionistas voltadas para o desenvolvimento ambiental sustentável” (UEPG, 2008, p. 75). E ainda ressalta que na avaliação das ações extensionistas será levado em consideração aspectos de relevância social, científica, cultural, ambiental, artística, institucional e/ ou econômica (UEPG, 2008).

Com relação a UNICENTRO, constatou-se que o documento preconiza que as ações de extensão sejam "orientadas por demandas coletivas referentes à qualidade de vida em seus aspectos político, social, ambiental e cultural [...] de modo a viabilizar soluções para os grandes problemas da sociedade [...] (COU/UNICENTRO, 2009, p. 21).

E por último, na análise dos documentos da UNIOESTE com relação aos programas e ações estratégicas para a extensão, identificou-se a "necessidade de inserir a educação ambiental e o desenvolvimento sustentável como componentes das atividades extensionistas (CEPE/UNIOESTE, 2007, p. 17).

Também verificou-se, que a UNIOESTE, apresenta a proposta de um plano de extensão que focaliza "a viabilidade de interferir na solução de problemas sociais e ambientais existentes na região, tais como: [...] gestão e educação ambiental [...], desenvolvimento sustentável e recuperação da mata ciliar". (CEPE/UNIOESTE, 2007, p. 16).

Em relação aos documentos analisados, houve maior destaque para a questão ambiental na extensão. É interessante constatar que está presente nos documentos a necessidade de estudos dirigidos as necessidades locais e regionais

Ficou bastante evidente nas análises que as questões relacionadas ao desenvolvimento sustentável estão presentes nos documentos institucionais. Todavia, os documentos não esclarecem o conceito de "desenvolvimento sustentável", que pode ser caracterizado como um conceito amplo que envolve várias especificidades. O que requer que os documentos apresentem proposições mais fundamentadas, com posicionamentos mais claros sobre tal concepção, e quais as diferentes dimensões que se associam ao termo.

Outro aspecto interessante, é o fato dos documentos apresentarem um viés que destaca a educação ambiental crítica, que nos documentos apresentam associadas as relações de complexidade entre homem e natureza, em um contexto de reconstrução e reorientação da sociedade. O que corrobora com Farias (2008), ao afirmar que a educação ambiental deveria (re)pensar as práticas produtivas e reprodutivas da educação na integração da problemática socioambiental às relações sociais, econômica, 
políticas e culturais. Contudo, apesar dos documentos evidenciarem a perspectiva crítica, é recorrente as menções a preservação ambiental.

Os documentos também apontam que a universidade deve construir espaços para discussão dos problemas ambientais, deixando de lado o distanciamento e a dicotomia nas relações sociais, políticas, econômicas, culturais e ambientais.

\section{CONSIDERAÇÕES FINAIS}

Da análise documental - Plano de Desenvolvimento Institucional (PDI) e Projeto Político-Pedagógico Institucional (PPI) - evidenciou-se que educação ambiental está inserida nos documentos de forma a subsidiar as práticas de ensino, pesquisa e extensão. Todavia, pode-se inferir a partir da análise dos documentos que as universidades concentram-se uma atenção maior da educação ambiental às ações extensionistas. Daí a necessidade de investigar, em estudos futuros, como as práticas extensionistas se operacionalizam, bem como, a influência nos territórios curriculares e na percepção dos sujeitos envolvidos.

As constatações identificadas neste estudo conduzem a reflexões que apontam que a ausência da efetivação da educação ambiental no contexto universitário não ocorre por falta de direcionamentos, nem de política institucional, mas pelo não enfrentamento das questões ambientais por parte da universidade. Farias (2008) faz uma observação bastante pertinente ao citar que a atuação com relação aos problemas ambientais não pode ser de competência exclusiva da esfera científica, uma vez que as decisões também são tomadas com base nos aspectos culturais, políticos e éticos da cidadania e autogestão, de onde deduz-se que a culpabilidade pela configuração da crise ambiental não deve ser atribuída à universidade. O que sucede é que as IES, a despeito de sua evolução, ainda apresentam grande dependência em relação aos agentes externos, principalmente do governo e do mercado, que condicionam e impedem sua autonomia (OLIVEIRA, 2012).

Um fator positivo, que a análise documental evidenciou é a existência do reconhecimento da importância da educação ambiental na universidade. Conforme o relatório elaborado pela Rede Universitária de Programas de Educação Ambiental para Sociedades Sustentáveis - RUPEA (2005) a proposta da educação ambiental na universidade não visa padronizar processos curriculares, mas compreender e fortalecer as iniciativas já existentes, bem como instigar processos nesta direção, não deixando de contemplar os contextos institucionais de autonomia das instituições e dos cursos, no que tange o planejamento curricular e pedagógico.

E importante salientar que o aprofundamento no tema ainda demanda tomada de decisão das instituições universitárias. De fato, o debate faz referência à necessidade de se reconhecer que a educação ambiental não constitui apenas uma dimensão da educação, mas uma nova função social da educação, responsável por transformações no campo educacional, com o objetivo de construir uma sociedade sustentável (LUZZI, 2005).

Cabe salientar, sob o ponto de vista de Loureiro (2012) que a proposta da educação ambiental é articular o problema ambiental com o contexto social, cultural, histórico, político, ideológico e econômico. O autor ainda enfatiza que a Educação Ambiental só apresentará resultados se for promovida em um processo dialético com a realidade, instigando mudanças culturais e sociais que possam propiciar a construção de uma sociedade ecologicamente prudente e justa.

No que diz respeito a responsabilidade da universidade, Raynaut e Zanoni (2011) destacam a formação de profissionais aptos a abordar os problemas, considerando a complexidade de suas dimensões. Logo, a universidade deve assumir o papel de agente de mudança da realidade ambiental, contribuindo com alternativas para a superação dos diversos problemas ambientais; e para isso, cada vez mais, torna-se necessário uma articulação das questões ambientais no ensino, pesquisa e na extensão.

Sorrentino et al. (2012, p. 22) apresenta que a educação ambiental na universidade pode cumprir dois papéis: o primeiro refere-se ao fato de integrar a própria instituição na questão ambiental, em um processo de ambientalização da instituição que deve permear as atividades de gestão ambiental, ensino, pesquisa e extensão. O segundo papel é a contribuição no processo de educar ambientalmente a sociedade, incitando práticas e ações educadoras.

A inserção ambiental no contexto universitário se depara com o processo de reformulação do conhecimento, suas relações e amplitude da temática. Contudo, pode-se inferir que, apesar de ser um 
processo ainda novo, a discussão ambiental já está sendo mais amadurecida, e desta forma "a universidade já começou a responder às demandas sociais de uma formação ambientalmente responsável para o exercício como profissional e como cidadão ambientalmente comprometido do aluno que está formando" (CARVALHO et al., 2012, p. 143). Com efeito, como sinaliza Morin (2003), "não se pode reformar a instituição sem uma prévia reforma das mentes, mas não se pode reformar as mentes sem uma previa reforma das instituições".

Neste contexto, a universidade assume a responsabilidade de preparar cidadãos conscientes de suas relações com o meio ambiente. Entretanto, tais iniciativas não devem apenas se basear em advertências, mas propiciar uma formação reflexiva e crítica, o que só será possível por meio de iniciativas que levem em conta o ensino, a pesquisa e a extensão.

\section{REFERÊNCIAS}

AGENDA 21 PARANÁ.. DECRETO Nº 2547. Cria o Fórum Permanente da Agenda 21 Paraná.Publicado no Diário Oficial No 6661 de 04/02/2004. Disponível em: http://celepar7cta.pr.gov.br/SEEG/sumulas.nsf/ fcc19094358873db03256efc00601833/9a39e437da06385503256e9900623454?OpenDocument. Acesso em: fev.2013.

CAPORLINGUA, V. H. A ambientalização de espaços educadores Sustentáveis. In: LEME, P. C. S.; PAVESI., A.; ALBA, D.; GONZÁLEZ., M. J. D.. (Org.). Visões e experiências ibero-americanas de sustentabilidade nas universidades. 1 ed. Madrid: Alambra, 2012, v. 1, p. 165-169.

CARVALHO, I. C. et al. Ambientalização curricular e pesquisas ambientalmente orientadas na PUCRS: um levantamento preliminar. In: LEME, P. C. S.; PAVESI, A.; ALBA, D.; G., M. J. D.. (Org.). Visões e experiências ibero-americanas de sustentabilidade nas universidades. 1 ed. Madrid: Alambra, 2012, v. 1, p. 137-143.

CEPE/UNIOESTE. Resolução Nº 270/2007-CEPE. Aprova o Projeto Político-Pedagógico Institucional PPPI da UNIOESTE-Universidade Estadual do Oeste do Paraná. Disponível em: http://www.unioeste.br/ gpc/docs/PPPI_Res_n_270_2007_CEPE.pdf. Acesso em jan. 2013

COU/UNICENTRO. Resolução No 7-COU/UNICENTRO - Universidade Estadual do Centro-Oeste, de 5 de janeiro de 2009. Aprova o Plano de Desenvolvimento Institucional, PDI, da UNICENTRO, para o quinquênio 2009 - 2013. Disponível em: http://www.unicentro.br/atos/200901291532523623.pdf. Acesso em: 14 de jan. 2013

FARIAS, C. R. O. A produção da política curricular nacional para a Educação Superior diante do acontecimento ambiental: problematizações e desafios. 2008. 215 f. Tese (Doutorado em Educação) - Universidade Federal de São Carlos, São Carlos, 2008.

FÁVERO, M. L. A. A Universidade no Brasil: das origens à Reforma Universitária de 1968. Educar, Curitiba, n. 28, p. 17-36, 2006. Editora UFPR.

FRANCO, M. L. P. B. Análise de conteúdo. 3. ed. Brasília: Líber Livro, 2008.

JACOBI, P. Educação ambiental, cidadania e sustentabilidade. Caderno de Pesquisa, Mar. 2003, n. 118, pág. 189-205. Disponível em: http://www.scielo.br/pdf/cp/n118/16834.pdf. Acesso em: 30 ago. 2012.

LOUREIRO, C. F. B. Trajetórias e fundamentos da educação ambiental. 4 ed. São Paulo: Cortez, 2012.

LÜDKE, M; ANDRÉ, M. E. D. A. Pesquisa em educação: abordagens qualitativas. São Paulo: EPU, 1986.

LUZZI, D. Educação Ambiental; Pedagogia, Política e Sociedade. In: PHILIPPI JR, e PELICIONI, M. C. F. (Ed.) A Educação Ambiental e Sustentabilidade. São Paulo: Manole. 2005. p. 381 - 400. 
MARTINS, G. de A. Estudo de caso: uma estratégia de pesquisa. 2 ed. 2 reimpr. São Paulo: Atlas, 2008.

MEC - MINISTÉRIO DA EDUCAÇÃO. Sistema de Acompanhamento de Processos das Instituições de Ensino Superior - SAPIEnS. Instruções para elaboração de plano de desenvolvimento institucional. Artigo 16 do Decreto ${ }^{\circ} 5.773$ de 09 de maio de 2006. Disponível em: http://www2.mec.gov.br/sapiens/pdi.html Acesso em: 07 de fev. de 2013.

MORIN, E. A cabeça bem-feita: repensar a reforma, reformar o pensamento. $8^{a}$ ed.Rio de Janeiro: Bertrand Brasil, 2003.

OLIVEIRA, H. T. de. Contextos e desafios na produção de sentidos sobre sustentabilidade e ambientalização da educação superior. In In: LEME, P. C. S.; PAVESI., A.; ALBA, D.; GONZÁLEZ., M. J. D.. (Org.). Visões e experiências ibero-americanas de sustentabilidade nas universidades. 1 ed. Madrid: Alambra, 2012, v. 1, p. $37-42$.

RAYNAUT, C.; ZANONI, M. Reflexões sobre princípios de uma prática interdisciplinar na pesquisa e no ensino superior. In. PHILIPPI Jr., A.; NETO, A. J. S. (Editores). Interdisciplinaridade em ciência, tecnologia \& inovação. Barueri: Manole, 2011, p. 143-208.

RUPEA - Rede Universitária de Programas de Educação Ambiental para Sociedades Sustentáveis. Mapeamento da Educação Ambiental em instituições brasileiras de Educação Superior: elementos para discussão sobre políticas públicas. Relatório Técnico (2005).

SEMA - Secretaria de Estado do Meio Ambiente e Recursos Hídricos. Guia Agenda 21 - 2009. Disponível em http://www.utp.br/agenda21utp/Guia_Agenda_21.pdf. Acesso em 10 de abr. 2013.

SORRENTINO, M. et al. Universidade, educação ambiental e políticas Públicas. In: LEME, P. C. S.; PAVESI, A.; ALBA, D.; G., M. J. D.. (Org.). Visões e experiências ibero-americanas de sustentabilidade nas universidades. 1 ed. Madrid: Alambra, 2012, v. 1, p. 19-27.

UEL (Universidade Estadual de Londrina). Plano de Desenvolvimento Institucional - PDI, 2010. Disponível em: www.uel.br/proplan/legislacao/PDI_2010_2015.pdf. Acesso em: 10 jan. 2013.

UEM (Universidade Estadual Maringá). Projeto Político-Pedagógico Institucional, 2009. Disponível em: http://www.scs.uem.br/2009/cep/013

cep2009_Anexo.htm. Acesso em: 11 de jan. 2013

UENP (Universidade Estadual do Norte do Paraná). Plano de Desenvolvimento Institucional - PDI, 2012. Disponível em: http://www.uenp.edu.br/index.php/piacd/doc_view/81-plano-de-desenvolvimento-institucional-2012-2017. Acesso em: 10 de jan. 2013.

UEPG (Universidade Estadual de Ponta Grossa). Projeto Pedagógico Institucional - PPI, 2008. Disponível em: http://www.uepg.br/proplan/pdi/PPI\% 202008-2012\%20-\%20Projeto\%20Pedagogico\%20Institucional. pdf. Acesso em: 11 de jan. 2013. 